\title{
Perceptions towards Cryptocurrency Adoption: A case of Saudi Arabian Citizens
}

\author{
Saad ALAKLABI ${ }^{1,2}$ and Kyeong KANG ${ }^{1}$ \\ ${ }^{1}$ University of Technology, Sydney, Australia \\ ${ }^{2}$ Shaqra University, Saudi Arabia
}

Correspondence should be addressed to: Saad ALAKLABI; saad.alaklabi@student.uts.edu.au

Received date: 18 November 2020; Accepted date: 22 January 2021; Published date: 2 July 2021

Academic Editor: Mohamad Aidil Bin Hasim

Copyright (C) 2021. Saad ALAKLABI and Kyeong KANG. Distributed under Creative Commons Attribution 4.0 International CC-BY 4.0

\begin{abstract}
The global financial market is influenced by relatively new technologies such as cryptocurrencies; namely Bitcoin, Ethereum, Litecoin, and others. Cryptocurrencies are a challenging area in finance that requires additional attention from the academic community as they can have a potentially large impact on society and the economy. This study aims to investigate the usability of digital money among the citizens of Saudi Arabia. Various factors that are related to user behavior and have an impact on user intent towards cryptocurrencies based on a combined approach are analyzed. The basis from which the authors started is The Theory of Reasoned Action (TRA), together with four other constructions: perceived risk (consisting of privacy risk, financial risk, and security risk), perception of enjoyment, perceived usefulness, and personal innovation. The method used to collect the data is a questionnaire. The results showed that variables such as subjective norms, security risk, perception of utility, and enjoyment influence the adoption and use of cryptocurrencies. These variables include the perception of pleasure as well as the perception of utility.
\end{abstract}

Keywords: Cryptocurrency, Digital currency, Bitcoin, Technology Adoption, TRA

\section{Introduction}

A cryptocurrency is a digital currency which represents digital records of certain values stored in digital databases. The goal of developing cryptocurrencies is to suppress printed money from the market and to establish a system that will not be under the supervision and control of the state and government. Bitcoin is the first cryptocurrency that was developed in 2009 (Satoshi, 2008) whose value is extremely growing; this is why it is often called the digital gold. In 2017, the value of cryptocurrencies was almost $\$ 800$ billion (Alzahrani and Daim, 2017) while in May 2019, bitcoin reached a market capitalization of nearly $\$ 100$ billion (Kaspersky, 2019). Some estimates suggest that by 2024, the number of Bitcoin users will reach as high as 200 million (Alzahrani and Daim, 2017). According to the Kaspersky Lab report, only $10 \%$ of people understand the meaning, significance, and system of cryptocurrencies, while $35 \%$ of people believe that cryptocurrencies are just a trend (Kaspersky, 2019). The data from this report has shown that $19 \%$ of

Cite this Article as: Saad ALAKLABI and Kyeong KANG (2021), "Perceptions towards Cryptocurrency Adoption: A case of Saudi Arabian Citizens ", Journal of Electronic Banking Systems, Vol. 2021 (2021), Article ID 110411, DOI: 10.5171/2021.110411 
people were hacked, and $15 \%$ of respondents were victims of cryptocurrency fraud. The lack of rigorous standards that can prevent fraud and hacking of cryptosystems leads to concerns and a lack of trust (Kaspersky, 2019) when it comes to the use of cryptocurrencies. Also, the biggest obstacles to understanding this whole system are the ignorance of computer technology, the terminology that is almost exclusively in English, as well as the lack of knowledge about cryptocurrencies (Kaspersky, 2019).

Before implementing any new technology, it is necessary to assess the possibility of its adoption. The founder and pioneer of the Bitcoin Investment Trust, Barry Silbert, argues that the adoption of cryptocurrencies is a process that occurs in five phases (Charalambos et al., 2015): (i) the experimentation phase, (ii) the early adoption phase, (iii) the venture capital phase, (iv).) wall street phase and (c) global consumer adoption phase. However, although theoretically, these phases are necessary, the actual adoption of cryptocurrencies depends on many other factors specific to each country and its economy. This research aims to assess how people in Saudi Arabia view the process of adopting cryptocurrencies and what intentions they have. To achieve this, the authors explored the TRA and related factors, namely subjective norms (SN), attitude (AT), and intent to adopt cryptocurrency (IACC). Besides, they investigated the perceived risk (PR), perceived usefulness (PU), perceived enjoyment (PE), and personal innovation (PI). TRA's model explains how the various factors associated with one's attitude relate to a particular behavior. According to this model, each individual will act without inhibitions and restrictions after the intention's formation, and changes can occur by including additional explanations. This theory has shown high validity with the possibility of comparing the results obtained in other studies. In this research, TRA will be the basis on which the authors will try to get answers to the formed hypotheses. This model has a good foundation and literature support and allows authors to identify gaps and reach correct conclusions. The TRA model is reliable in determining users' affinity towards the use of cryptocurrencies, especially since it is a new technology. This research introduces three new aspects of this model:

1. It explores the factors that influence the intention of Saudi citizens to become cryptocurrency users.

2. The study includes participants who use social networks such as Twitter, which implies that they are technologically literate.

3. This study includes participants who already have some prior knowledge of cryptocurrencies, which will provide new insights into how people who already know the new technology perceive it and how likely they are to become users.

\section{Theoretical Background and Model Development}

\section{Related Works}

Many studies have used these models or a combination of these models to investigate influential factors not only in the field of cryptocurrencies but also in other areas. Concerning cryptocurrency adoption, the authors aimed to investigate the degree of acceptance of blockchain technology for financial transactions. The study involved 277 participants, of whom $72 \%$ were men and $28 \%$ were women (Albayati, Kim and Jeung Rho, 2020). This study's findings showed that trust is the main variable influencing the acceptance of a new technology, while regulatory support and experience affect trust (Albayati, Kim and Jeung Rho, 2020). In contrast, in the work of Ku-Mahamud et al. (2019), the results showed that most respondents believe that blockchain technology and cryptocurrencies are stable and secure. The study aimed to analyze the factors influencing the adoption of cryptocurrencies (i.e., Awareness, Adoption, and Trust) in Malaysia on a sample of 304 respondents (Ku-Mahmud et 
al., 2019).

Sohaib et al. (2019) developed a model by analyzing factors such as technological readiness (optimism, innovation, discomfort, and uncertainty), acceptance of technology, perceived ease of use and utility, and intention to use cryptocurrency on a sample of 160 participants (56\% men and $44 \%$ women). The main impacts were estimated using partial least squares SEM (PLS-SEM), while Artificial Neural Networks (ANN) were used to rank the most significant factors (Sohaib et al., 2019). The results of the study showed that perceived ease of use is positively correlated with optimism, while perceived ease of use is negatively correlated with discomfort, followed by uncertainty. The results also showed that perceived ease of use has the strongest effect on perceived utility, while perceived utility has a highly significant positive effect on the intention to use cryptocurrencies (Sohaib et al., 2019).

The adoption of bitcoin from the monetary exchange attitude was investigated by Wood et al. (2018) using TAM and the development innovation diffusion theory. The study was conducted on 121 respondents and showed that relative advantage, easy use, visibility, and compatibility have a big positive impact on bitcoin utilization (Wood et al., 2017).

Wood et al. (2017) explored the seen advantage and chance related to bitcoin utilization. The authors created TAM based on a test of 86 respondents (95\% were male). The results showed that the fluctuating esteem, the hazard of moneyrelated misfortunes, and the need for customer assurance are the most factors influencing people's intention to utilize bitcoin. However, ease of utilizing has the weakest impact on bitcoin utilization (Abramova \& Böhme, 2016). The acceptance of Bitcoin was also examined in the work of Lee Won (2018), utilizing TAM, which included 224 respondents. The conclusions showed that seen convenience has the most grounded impact on the intention to utilize Bitcoin (Lee Won, 2018).
In the study of Ayedh et al. (2020), elements affecting the investment in the Bitcoin market were investigated. The study covered 200 Muslim respondents (25\% male and 75\% female) in Malaysia, and the factors have been investigated using SEM. The factors that were determined were extracted from TPB, TAM, and the diffusion of innovations theory. It was observed that facilitating conditions, awareness, and compatibility have a tremendous effect on making investments in Bitcoin [25]. On the contrary, trust, profitability, subjective norms, and ease of use had been discovered not to have a widespread effect on Bitcoin funding (Ayedh et al., 2020).

Al Shehhi, MayadaOudah and Zeyar Aung (2014) analyzed the factors that affect the popularity and value of cryptocurrency. The study looked at eight cryptocurrencies: Bitcoin, Litecoin, Ripple, Peercoin, Dogecoin, Kittehcoin, Darkcoin, and Vertcoin. The sample included 134 online users, with $95.5 \%$ male and $4.5 \%$ female participants. Studies show that young participants choose cryptocurrency based on name and logo. Additionally, participants believe in cryptocurrency considering that ease of mining, strong community, privacy, anonymity, value and popularity (Al Shehhi, MayadaOudah and Zeyar Aung, 2014).

Zarifis et al. (2018) Investigated consumer confidence in digital currency transactions using a sample of 41 participants (23 men and 18 women). The results suggest that those who understand technological innovations have more confidence in these technologies than those who do not. It has also been shown that confidence can be boosted if the government is involved in regulating such technologies (Zarifis et al., 2018).

The factors associated with Litecoin cryptocurrency were examined using a sample of 119 participants (Gibbs, and SuwareeYordchim, 2014). This study explores four main factors. The first factor recommends that future professional training should be included in Litecoin

Saad ALAKLABI and Kyeong KANG, Journal of Electronic Banking Systems,

DOI: $10.5171 / 2021.110411$ 
development, while the second one suggests that the concept of digital currency should be more understandable, and its benefits should be presented. The third factor indicates the need for education in cryptocurrency, while the last factor indicates that the respondents did not know what Litecoin was, which in turn indicates the need for education (Gibbs and SuwareeYordchim, 2014).

\section{Model Development}

To evaluate cryptocurrency users' behavior, the authors adopted the TRA model and included three additional constructs - PR, PU, and PE. TRA was developed by Fishbein in 1967 and aimed to explain the relationship between a particular subject or action and human attitudes toward human behavior (Fishbein, 1967). It is used to predict actions based on people's behavior and past behavior. The main concepts of TRA are attitude, subjective norms, and behavioral objectives.

The purpose of the behavior is the main factor influencing behavior and is driven by attitudes and norms. If the attitude towards that behavior is strong, and if subjective norms allow such behavior, the person will behave. The behavioral objective (Hale et al., 2002) can be expressed as:

$$
B I=(A B) W_{1}+(S N) W_{2}
$$

where $A B$ is a person's attitude toward behavior, SN is a person's subjective norm related to a particular behavior, and $\mathrm{W}$ is the weights. The attitude towards $\mathrm{AB}$ behavior (Ajzen and Albarracín, 2007) can be expressed as:

$$
A B=\sum b_{i} e_{i}
$$

where $b_{i}$ is the strength of the belief that a particular behavior will have a certain outcome $i$, and $e_{i}$ is the evaluation of outcome $i$. Furthermore, the subjective norm can be expressed as:

$$
S N=\sum n b_{i} m c_{i}
$$

where nbi are normative beliefs connected to a certain outcome $\mathrm{i}$, and mci is the motivation to comply to the particular behavior.

Attitudes can be defined as beliefs towards a particular behavior (Ajzenm and Albarracín, 2007). When these beliefs come together, they create a positive, negative, or neutral attitude toward behavior (Ajzenm and Albarracín, 2007). The literature suggests that if a person believes that the result of a particular behavior will be positive (Ajzenm and Albarracín, 2007; Fishbein, 1967), he/she will develop a positive attitude towards that behavior, and vice versa. A study by Agustina (2019) showed that this behavior significantly affects the intent to use cryptocurrency trading applications. Therefore, to examine the effect of attitude on Saudi citizens' intention to adopt cryptocurrencies, the following hypothesis has been proposed:

H1: Attitude has a positive effect on the intention to adopt cryptocurrencies.

Behavior is also influenced by subjective norms, which can be defined as "perceived social pressure to perform or not perform the behavior" (Ajzen and Albarracín, 2007). These social pressures stem from expectations from major groups and individuals' views, shaping the perception of the individual's behavior. People mingle with their environment and social sector. Therefore, it is important to consider the need to conform to others' perceptions following subjective standards (Fishbein and Ajzen, 1975). Social influence has been found to influence behavioral intention to introduce cryptocurrency. In this study, the following hypothesis is proposed:

H2: Subjective norm has a significant positive effect on introducing cryptocurrency.

As mentioned above, in addition to TRA constructs, this study also looked at PR, PU, and PE. PR shows how consumers are aware of the risks associated with using a certain technology. This can be defined as the notion of the undesirable consequences of purchasing or using a particular 
product/technology (Faqih, 2016). PR covers many aspects, including privacy risk, security risk, and financial risk. Privacy risk is the privacy of one's information, and security risk refers to one's uneasiness about using certain technologies. Economic risk is related to the cost of using a particular technology. In previous studies, PR uses several technologies, including mobile banking (Thakur and Srivastava, 2014; Kishore and Sequeira, 2016), internet banking (Martins, Oliveira and Popovič, 2014) and ecommerce (Belkhamza and Wafa, 1970; Lai and Tang, 2018), as well as consumer purchasing intent (David et al., 2001; Kannungo and Jain, 2004.). It is shown to influence intent. Considering that cryptocurrencies carry potential risks that can affect user attitudes and behavior, the following hypotheses are proposed:

H3a: Privacy Risk has a significant negative effect on attitude.

H3b: Security Risk has a significant negative effect on attitude.

H3c: Financial Risk has a significant negative effect on attitude.

H4a: Privacy Risk has a significant negative effect on the intention to adopt cryptocurrency.

H4b: Security Risk has a significant negative effect on the intention to adopt cryptocurrency.

H4c: Financial Risk has significant negative effect on the intention to adopt cryptocurrency.

PU is interested in people's opinions about how behavior improves people's performance (Davis, 1989). Davis found that PU has a weak relationship with attitude (Davis, 1989). He added that the intention to adopt this technology has a strong and direct impact on PU. PU is also affected by the cost-effectiveness model (Davis, 1989). This is explained by the fact that people make decisions regarding a certain technology based on the effort required to use that technology along with its benefits. Also, PU has been shown to have a significant impact on using cryptocurrencies (Ajay, Shrestha and Vassileva, 2019). PUs are so subjective (Davis at al., 1989) that they are highly dependent on the user's capabilities and cannot be used independently of other components to explain the use of a particular technology. Therefore, considering the importance of the combined approach, the authors will investigate the relationship between PU, trends and the purpose of adopting cryptocurrencies, and propose the following hypotheses:

H5: Perceived Usefulness has a significant positive effect on attitude.

H6: Perceived Usefulness has a significant positive effect on the intention to adopt cryptocurrency.

PE can be defined as "engaging in an activity" because of an individual's interest or performance. Numerous studies have shown that PE influences using technologies such as mobile services (Moon and Kim, 2001), mobile learning (Al-Zoubi and Ali, 2019; Huang, Lin and Chuang, 2007), and financial services. When considering cryptocurrencies, it is understood that the repurchase of bitcoins and other cryptocurrencies is significantly affected by enjoyment. PE has been found to have a strong influence on perceived efficacy (Shrestha and Vassileva, 2019). Therefore, to investigate the impact of adopting PE and cryptocurrency in Saudi Arabia, the following hypotheses have been suggested:

H7: Perceived Enjoyment has a significant positive effect on attitude.

H8: Perceived Enjoyment has a significant positive effect on the intention to adopt cryptocurrency.

Researchers believe that Personal Innovation (PI) is one of the personality traits that play a role in adopting technology (Agarwal and Prasad, 1998). It is defined as "the degree to which an individual or other adoption units adopt new ideas relatively earlier than other members of the social system" (Rogers 2003 , p. 22). Personal innovation can also be used to reach a group of people who are normally at risk of using an innovation. The link between personal innovation and behavioral intentions is present in the 
literature (Lu, 2014). As discussed in the literature review, PI was included to predict people's behavioral intention to use technology. For example, individual differences, including the level of risk and personal innovation, have been associated with implementing e-commerce technologies (Agarwal and Prasad, 1998; Alalwan et al., 2018; Thakur and Srivastava, 2014; Williams, 2018) and they are also used in the context of electronic commerce in Saudi Arabia (Al-Jabri, 2015) and mobile learning (Al-Hujran, Al-Lozi \& Al-Debei, 2014). Besides, among previous studies that confirmed the importance of intellectual property, there were several concerns for which the information security literature suggested contextualizing the use of public relations. For example, public relations can be used differently depending on the context and innovation under study. The following hypotheses were proposed:

H9: Personal innovation will have a positive effect on attitudes towards the adoption of cryptocurrency in Saudi Arabia.

H10: Personal innovation will have a positive effect on Saudi Arabia's intention to introduce cryptocurrency.

The proposed model is presented in Figure 1.

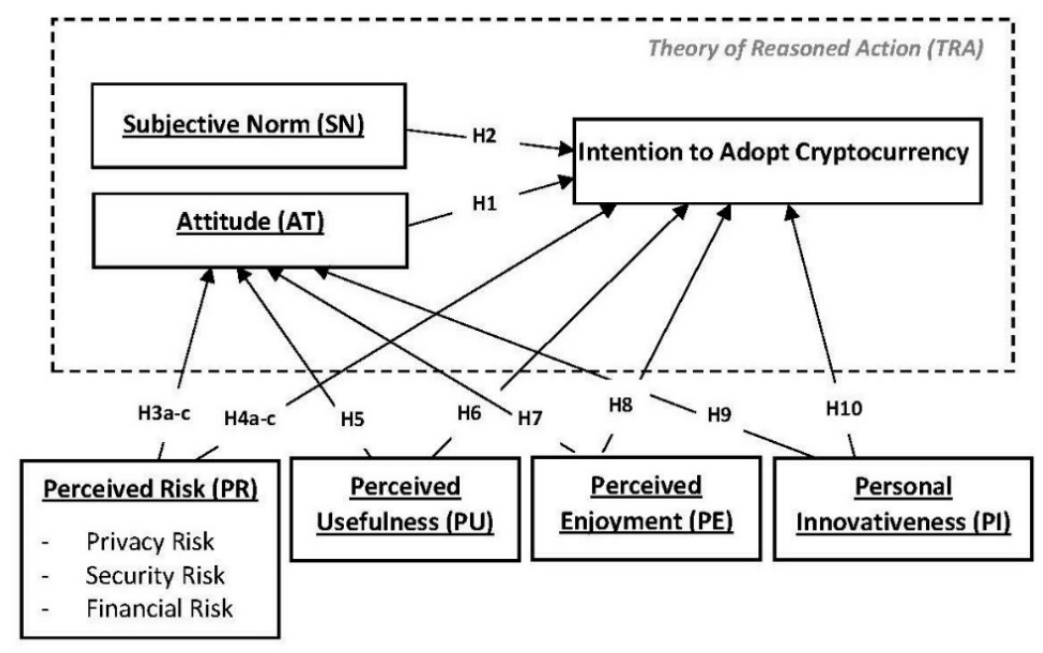

Figure 1: The proposed model

\section{Research Methodology}

The research methodology included a survey consisting of validated elements and concepts from previous studies. The proposed model is a combination of factors related to TRA (i.e., subjective standard, attitude, and intent to adopt the technology) and perceived risk, usefulness, enjoyment and personal innovativeness (as shown in Figure 1). All constructs consist of several elements from the literature.

The survey was conducted by a questionnaire method. An online survey was created consisting of three parts: questions related to demographic data, profiles of knowledge about cryptocurrencies, and model building questions. Survey responses were collected from September to November 2019. According to social media statistics published by Global Media Insight (2019), $56 \%$ of Saudi Arabia's population have active Twitter accounts (18.96 million people), so a link to the survey was posted on Twitter and cryptocurrency users shared it (that is, users who tweeted and commented on cryptocurrencies). The selection criteria included cryptocurrency users who lived in Saudi Arabia, used 
Twitter, and were 18 years of age or older. The Qualtrics platform was used to poll participants on the Internet, encouraging participants to participate in the survey. After receiving 562 participants, incomplete questionnaires were removed, resulting in 368 questionnaires included in the analysis. Respondents agreed to participate by filling out the question. The questionnaire was anonymous and kept secret throughout the study.

The data collected were analyzed using SPSS, and the SEM was constructed using AMOS.

\section{Results}

\section{Descriptive statistics}

Table 1 shows the descriptive statistics of the respondents' profiles. It can be seen that $95 \%$ of the respondents are male. This percentage represents the population of people using cryptocurrencies.

Considering the respondents' age, it can be seen that $45 \%$ of the respondents are 30 39 years old, followed by 20-29 years old (36\%) and 40-49 years old (16\%). Since cryptocurrencies rely on the Internet, and the first cryptocurrency, Bitcoin, was developed in 2009, it has become more attractive to young people (Alaeddin and Altounjy, 2018).

In terms of nationality and language, 88\% of the respondents are Saudi Arabians. Therefore, $88 \%$ of them are expected to speak Arabic, and $12 \%$ are expected to speak English (Table 1). Besides, 61\% of the respondents have a bachelor's degree, followed by $19 \%$ with a graduate degree and $12 \%$ with a university degree. Only $8 \%$ of the respondents have a high school degree.

In terms of location, the maximum number of participants who participated in this survey and knew about cryptocurrencies is in the central (35\%) and western (24\%) regions of the country. This is in line with current development statistics. The central region of Saudi Arabia has the highest Human Development Index in the country, followed by the north and west regions. In addition, $15 \%$ of the respondents are from the east part of the country, $14 \%$ are from the north, and $13 \%$ are from the south.

Table 1: Descriptive statistics of the dataset

\begin{tabular}{|l|c|c|c|}
\hline Item & Values & Frequency & Percentage \\
\hline Gender & Male & 367 & 95.3 \\
\hline & Female & 18 & 4.7 \\
\hline Age & $<20$ & 7 & 1.9 \\
\hline & $20-29$ & 130 & 35.6 \\
\hline & $30-39$ & 165 & 45.2 \\
\hline & $40-49$ & 59 & 16.2 \\
\hline & $\geq 50$ & 4 & 1.1 \\
\hline Nationality & Saudi & 337 & 88.2 \\
\hline & Non-Saudi & 45 & 11.8 \\
\hline User & English & 37 & 12.2 \\
\hline language & Arabic & 29 & 87.8 \\
\hline Education & High school & 44 & 7.8 \\
\hline & College degree & 226 & 11.9 \\
\hline & Bachelor's degree & 71 & 61.1 \\
\hline & Postgraduate degree & 130 & 19.2 \\
\hline Part of Saudi & Center & 48 & 35.0 \\
\hline & South & 87 & 12.9 \\
\hline & West & 52 & 23.5 \\
\hline & North & 14.0 \\
\hline
\end{tabular}

Saad ALAKLABI and Kyeong KANG, Journal of Electronic Banking Systems, 


\begin{tabular}{|l|l|l|l|}
\hline Item & Values & Frequency & Percentage \\
\hline & East & 54 & 14.6 \\
\hline
\end{tabular}

Cryptocurrency Knowledge Profile

In relation to the cryptocurrency knowledge profile, namely participants' knowledge of cryptocurrencies, various aspects were reviewed (Table 2). It is important to note that the questions in this section attempt to gauge participants' familiarity with cryptocurrencies. First, participants were asked if they had a technical background. Percentages of participants are almost evenly distributed because $52 \%$ of them have a technical background, and $48 \%$ do not have a technical background. This is an interesting finding as it suggests that participants may be interested in cryptocurrencies regardless of their professional or educational background. Also, participants had to rate their knowledge of cryptocurrencies, and the results showed that most participants (69\%) knew about cryptocurrencies, followed by $21.5 \%$ of the participants who rank themselves in the initial rank. Only $9.3 \%$ of the participants said that they are cryptocurrency experts, while $0.3 \%$ said that they do not know cryptocurrency. These findings confirm the need for this technology and the participants' interest in learning more about it and entering the cryptocurrency market. More than half of the respondents $(52.7 \%)$ have already participated in cryptocurrency activities such as trading, investing, analytics, etc., mostly with Bitcoins $(10.9 \%)$, followed by Ethereum $(9.6 \%)$. In practice, this situation means that people with practical knowledge of cryptocurrency may differ in their responses. Therefore, an additional study of respondent representation is necessary to determine statistical bias. The other types of cryptocurrencies (REBL, Litecoin, Tron and others) are much less represented in the observed population.

Table 2: Cryptocurrency knowledge profile

\begin{tabular}{|c|c|c|c|}
\hline Item & Values & Frequency & Percentage \\
\hline \multirow[t]{2}{*}{ Do you have any technology background? } & Yes & 184 & 47.8 \\
\hline & No & 201 & 52.2 \\
\hline \multirow[t]{4}{*}{$\begin{array}{l}\text { How do you classify your knowledge about } \\
\text { cryptocurrency? }\end{array}$} & No knowledge & 1 & 0.3 \\
\hline & Beginner & 83 & 21.5 \\
\hline & Knowledgeable & 266 & 68.9 \\
\hline & Expert & 36 & 9.3 \\
\hline \multirow[t]{2}{*}{$\begin{array}{l}\text { Have you ever participated in cryptocurrency } \\
\text { activities? }\end{array}$} & Yes & 202 & 52.7 \\
\hline & No & 181 & 47.3 \\
\hline \multirow[t]{8}{*}{$\begin{array}{l}\text { Which cryptocurrency activity have you } \\
\text { participated in? }\end{array}$} & Bitcoin & 42 & 10.9 \\
\hline & Ethereum & 37 & 9.6 \\
\hline & REBL & 15 & 3.9 \\
\hline & Litecoin & 14 & 3.6 \\
\hline & Tron & 11 & 2.8 \\
\hline & XRP & 7 & 1.8 \\
\hline & Binance & 7 & 1.8 \\
\hline & Cardano & 5 & 1.3 \\
\hline
\end{tabular}

Saad ALAKLABI and Kyeong KANG, Journal of Electronic Banking Systems, 


\begin{tabular}{|l|l|c|c|}
\hline Item & Values & Frequency & Percentage \\
\hline & Others & 66 & 17.1 \\
\hline
\end{tabular}

\section{Construct Reliability and Internal consistency}

The reliability of the first scale needs to be verified to work with new factors. Cronbach developed Cronbach's Alpha as a measure of the internal consistency of the test/scale [62]. It can take values in the range of 0 to 1,1 indicating good reliability. However, Cronbach's most popular alpha values range from 0.70 to 0.95 (Nunnally, 1994).

Cronbach's first construction had an alpha PR of five items, valued at 0.92 , indicating the items' high reliability inside the construction. The SR consists of two items with an alpha value of 0.817, which confirms the element's reliability. The FR construct consists of five items with an alpha value of 0.884 . For PE, the obtained alpha value is 0.913 , with four items. The PU consists of five items with an alpha value of 0.908 , while SN construction has an alpha value of 0.844 with two items. Looking at the perspective, Cronbach's Alpha got a value of 0.90 with five construction items. Finally, the IACC construction consisted of four items, valued at 0.887 .

Considering each item factor's loading, all loads are above 0.6, which indicates a strong relationship between constructs and constructs items. These results are presented in Table 3.

Table 3: Reliability of constructs

\begin{tabular}{|c|c|c|c|}
\hline Latent variable & Indicators & Factor loading & Cronbach's alpha \\
\hline \multirow[t]{5}{*}{$\mathrm{PR}$} & PR1 & 0.783 & 0.920 \\
\hline & PR2 & 0.934 & \\
\hline & PR3 & 0.876 & \\
\hline & PR4 & 0.849 & \\
\hline & PR5 & 0.752 & \\
\hline \multirow[t]{2}{*}{ SR } & SR1 & 0.645 & 0.817 \\
\hline & SR2 & 0.976 & \\
\hline \multirow[t]{5}{*}{ FR } & FR1 & 0.7 & 0.884 \\
\hline & FR2 & 0.897 & \\
\hline & FR3 & 0.834 & \\
\hline & FR4 & 0.724 & \\
\hline & FR5 & 0.615 & \\
\hline \multirow[t]{4}{*}{$\mathrm{PE}$} & PE1 & 0.802 & 0.913 \\
\hline & PE2 & 0.9 & \\
\hline & PE3 & 0.908 & \\
\hline & PE4 & 0.772 & \\
\hline \multirow[t]{5}{*}{$\mathrm{PU}$} & PU1 & 0.793 & 0.908 \\
\hline & PU2 & 0.853 & \\
\hline & PU3 & 0.908 & \\
\hline & PU4 & 0.903 & \\
\hline & PU5 & 0.637 & \\
\hline \multirow[t]{3}{*}{ SN } & SN1 & 0.643 & 0.844 \\
\hline & SN2 & 0.959 & \\
\hline & SN3 & 0.713 & \\
\hline
\end{tabular}

Saad ALAKLABI and Kyeong KANG, Journal of Electronic Banking Systems, 


\begin{tabular}{|l|c|c|c|}
\hline Latent variable & Indicators & Factor loading & Cronbach's alpha \\
\hline & SN4 & 0.909 & \\
\hline PI & SN5 & 0.785 & \\
\hline & PI1 & 0.761 & 0.805 \\
\hline & PI2 & 0.731 & \\
\hline AT & PI3 & 0.804 & 0.901 \\
\hline & AT1 & 0.787 & \\
\hline & AT2 & 0.812 & \\
\hline & AT3 & 0.813 & \\
\hline & AT4 & 0.734 & \\
\hline IACC & AT5 & 0.768 & \\
\hline & IACC1 & 0.765 & \\
\hline & IACC2 & 0.888 & \\
\hline & IACC3 & 0.67 & \\
\hline & IACC4 & 0.594 & \\
\hline
\end{tabular}

\section{Model Results}

The following table shows the compatibility indices of the structural model. The Chi-Square value of the conceptual model is significant $(\chi 2=$ 1114.486, $\mathrm{p}=0.000$ ), ensuring a good model fit. The GFI value shows a satisfactory fit with a value greater than 0.8
[64]. The TLI, CFI, and IFI values should be close to 1 to indicate the best fit, as shown in the results of Table 4 (Hair et al., 2010). The RMSEA shows a good fit, as the value is less than 0.05 (Hair et al., 2010). The most important measures to note is the AIC or Akaike Information Criterion. Taking this value into account, the model obtained a score of 1324.49 .

Table 4: Model results

\begin{tabular}{|l|l|}
\hline Fit indices & Value \\
\hline$\chi 2$ & 1114.486 \\
\hline $\mathrm{df}$ & 636 \\
\hline ANOVA $p$ & 0.000 \\
\hline GFI & 0.865 \\
\hline TLI & 0.949 \\
\hline CFI & 0.953 \\
\hline IFI & 0.954 \\
\hline RMSEA & 0.044 \\
\hline AIC & 1324.486 \\
\hline
\end{tabular}




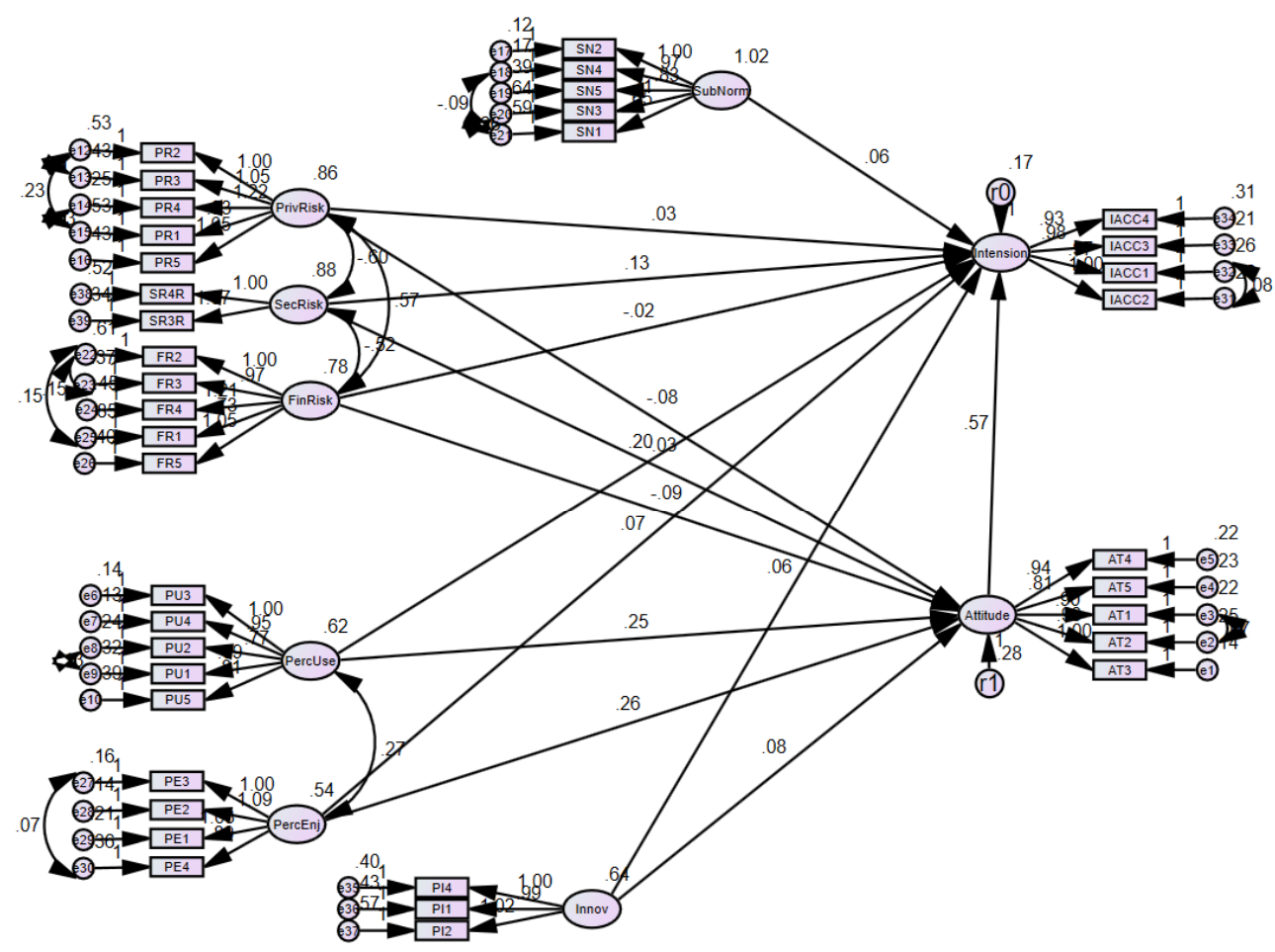

\section{Hypothesis Testing}

It can be observed the t-value and its corresponding significance (p-value) are used to decide whether to accept or reject the hypothesis (Table 6).

The first hypothesis, "Attitude has a significant positive impact on the intent to adopt cryptocurrencies," is supported based on significant $t$-values $(t=9,116, p=$ $0.000)$. This result supports most of the results in the literature. In particular, Doblas (2019) found that attitudes have a significant impact on adopting cryptocurrencies. "One unit increase in attitude increases the probability of hiring 11.49 times, while other variables are constant". Kings, Wang, Dou and Zhou (2008) also found that attitudes have a significant impact on product adoption, and Mutamarba (2019) found a significant positive effect of attitudes on the intent to adopt cryptocurrencies.

The second hypothesis, "subjective norms have a significant positive effect on the intent to adopt cryptocurrencies," is also supported $(\mathrm{t}=2.189, \mathrm{p}=0.029)$. The construction of subjective norms related to cryptocurrencies was studied in the work of Mutambara (2019) having a negative effect, but not statistically significant. On the contrary, Schaupp and Festa (2018) found that subjective norms are an important factor influencing the intent to use cryptocurrencies. This supports the authors' assumptions and hypothesis.

There was not enough evidence to support the assumption that privacy risk has a significant negative effect on behavior $(\mathrm{t}=$ $-1.405, p>0.05$ ), nor does security risk have a significant negative effect on behavior. $(\mathrm{t}=-0.556, \mathrm{p}=0.578)$. This finding is consistent with the literature (Walton and Johnston, 2018) where researchers found that the security risk does not affect attitudes to the intent to use bitcoin. The H3c hypothesis, "Financial risk has a significant negative effect on behavior", does not support $95 \%$ of the confidence interval $(t=.61 .648, p=0.099)$, so it can be rejected. Furthermore, there 
was not enough evidence that the adoption of cryptocurrency $(\mathrm{t}=0.503, \mathrm{p}=0.615)$ is impacted by privacy. Still, there was also evidence that cryptocurrency $(\mathrm{t}=2.510$, $\mathrm{p}=0.012$ ) is negatively affected by a security risk. 2.510, $\mathrm{p}=0.012$ ).

Considering $\mathrm{H} 4 \mathrm{c}$, it cannot be concluded that the adoption of cryptocurrency is negatively affected by the severity of the financial risk, as the value exceeds 0.05 , while the $t$ value is less than \pm 2 . These results are in line with some studies in the literature which show that the intention to use PR construct is not important enough to explain using cryptocurrency (Oliva, Pelegrín-Borondo and Matías-Clavero, 2019; Gibbs and Yordchim, 2014). This means that people who use cryptocurrencies expect to be at risk, so they may not feel threatened by risk as an important factor when deciding to use cryptocurrencies. These results also show that people are generally more concerned about losing money and information (i.e., security risk) than current costs (i.e., financial risk) and losing personal information (i.e., privacy risk).

This study found that the perceived usefulness $(\mathrm{t}=5.499, \mathrm{p}=0.000)$ was positively correlated with the intention to adopt cryptocurrency $(\mathrm{t}=4.558, \mathrm{p}=0.000)$. Considering the factors that influence the adoption of cryptocurrency, this is in line with some of the literature findings, where PU positively affects the intensity and behavior of cryptocurrency adoption (Sohaib et al., 2019; Won, 2018). Albayati et al. (2020) found a statistical effect of strategic orientation, social impact, selfefficacy, and novelty on two mediation variables (perceived usefulness and ease of use). Furthermore, they found that the two mediation variables have a significant effect on adopting blockchain technology (Nuryyev et al., 20120). The results obtained in this study validate these findings, as the perceived utility has a significant effect on adopting cryptocurrency. Furthermore, MendozaTello et al. (2018) have found that the most influential factor in adopting cryptocurrency is perceived usefulness.

Predictable enjoyment also positively affects the trend $(\mathrm{t}=5.241, \mathrm{p}=0.000)$ and the intensity of adopting cryptocurrency $(\mathrm{t}$ $=4.558, \mathrm{p}=0.000)$. PE has been found to influence the decision to use technology in numerous studies, including the significant influence of PE on the intent to repurchase bitcoins (Athar Nadeem et al., 2020), mobile instant messaging (GuychNuryyev et al., 2020), social networks (Zong, Yang and Bao, 2019), or use of blockchain technology (Shrestha and Vassileva, 2019). Finally, individual innovation's positive effect on trends is not conducive to a 95confidence interval $(t=1.900, p=0.057)$, thus this assumption is rejected. The same effect was observed in the last hypothesis, where the effects of individual innovation on adopting cryptocurrency were examined. The results show that this hypothesis is not supported $(\mathrm{t}=1.640, \mathrm{p}=$ 0.100 ).

Table 6: Hypothesis test results

\begin{tabular}{|l|l|l|l|l|l|}
\hline Hypothesis & Path & $\begin{array}{c}\text { Path } \\
\text { coefficient }\end{array}$ & t-value & p-value & Result \\
\hline H1 & AT $\rightarrow$ IACC & 0.565 & 9.116 & 0.000 & Supported \\
\hline H2 & SN $\rightarrow$ IACC & 0.058 & 2.182 & 0.029 & Supported \\
\hline H3a & PR $\rightarrow$ AT & -0.080 & -1.405 & 0.160 & Not supported \\
\hline H3b & SR $\rightarrow$ AT & -0.031 & -0.556 & 0.578 & Not supported \\
\hline H3c & FR $\rightarrow$ AT & -0.093 & -1.648 & 0.099 & Not supported \\
\hline H4a & PR $\rightarrow$ IACC & 0.026 & 0.503 & 0.615 & Not supported \\
\hline H4b & SR $\rightarrow$ IACC & 0.126 & 2.510 & 0.012 & Supported \\
\hline H4c & FR $\rightarrow$ IACC & -0.022 & -0.432 & 0.665 & Not supported \\
\hline
\end{tabular}

Saad ALAKLABI and Kyeong KANG, Journal of Electronic Banking Systems, 


\begin{tabular}{|l|l|l|l|l|l|}
\hline Hypothesis & Path & $\begin{array}{c}\text { Path } \\
\text { coefficient }\end{array}$ & t-value & p-value & Result \\
\hline H5 & PU $\rightarrow$ AT & 0.255 & 5.499 & 0.000 & Supported \\
\hline H6 & PU $\rightarrow$ IACC & 0.201 & 4.558 & 0.000 & Supported \\
\hline H7 & PE $\rightarrow$ AT & 0.262 & 5.241 & 0.000 & Supported \\
\hline H8 & PE $\rightarrow$ IACC & 0.068 & 4.558 & 0.000 & Supported \\
\hline H9 & PI $\rightarrow$ AT & 0.079 & 1.900 & 0.057 & Not supported \\
\hline H10 & PI $\rightarrow$ IACC & 0.061 & 1.640 & 0.100 & Not supported \\
\hline
\end{tabular}

\section{Discussion and Conclusion}

The purpose of this research is to assess the factors influencing the adoption of cryptocurrencies. In particular, this study used an integrated approach by combining the TRA model with three other constructs, namely $\mathrm{PR}, \mathrm{PU}$, and $\mathrm{PE}$, to observe the influence of these factors on cryptocurrency users' attitudes and their intention to use them. Eight hypotheses were tested using data from a survey. The results showed that the intention to introduce cryptocurrency is influenced by attitudes, subjective norms, perceived benefits, and enjoyment. As for personal innovation, privacy risk, and financial risk, which are the dimensions of perceived risk, they were found to be not associated with the intention to adopt cryptocurrency; however, the security risk was found to affect behavioral intent. In light of attitudes, this study shows that perceived risk does not affect users' attitudes towards using cryptocurrencies. In contrast, perceived usefulness and perceived entertainment significantly affect consumers' attitudes. These results are not surprising. Cryptocurrency represents a relatively new technology, so not enough information is available to the general population. That being said, consumers are expected to be influenced by others' opinions (i.e., thematic theories). Furthermore, consumers are attracted to technologies they can understand and which help them work faster.. When deciding to use cryptocurrencies, consumers are more concerned about the security of their data and accounts. The intention to adopt cryptocurrencies in Saudi Arabia is influenced by the consumer's attitude, which is greatly influenced by the benefits of technology and the consumer's satisfaction from using such technology.

The goal of this paper is to identify the factors affecting cryptocurrency adoption through a questionnaire involving questions related to TRA. There were more males than females in the sample, which can be considered a limitation of the study; however, this is also consistent with the literature findings, such as in the work of Shehhi, Oudah and Aung (2014) which investigated the reasons for choosing cryptocurrency using a sample of respondents of which $95 \%$ were male. Another study that examined cryptocurrencies, in particular, found that the usefulness of bitcoins included more men than women $(75 \%$ of the sample), confirming that cryptocurrencies were mostly male-dominated. Women are also represented in the cryptocurrency trade (Alshamsi, and Andras, 2019). A study by Vejacka and Palova (2019) examined gender differences among Slovak citizens, which affect their attitudes towards cryptocurrencies. Male respondents generally have more information about cryptocurrencies, using them more frequently for payments. Cryptocurrencies are more likely to be adopted by men than women. In general, men were found to be more positive about cryptocurrencies than women (Vejacka and Palova, 2019), which explains why women are underrepresented and generally not interested in cryptocurrencies.

Another possible limitation of this study is that the sample was composed of younger people; hence the results might not represent the older population well. Comparing these proportions to the proportion of educated people aged

Saad ALAKLABI and Kyeong KANG, Journal of Electronic Banking Systems,

DOI: $10.5171 / 2021.110411$ 
between 20-39 years old, the participants in this study have higher educational degrees, and respondents with high school degrees or college degrees have a small representation in the sample compared to the known data of the General Authority for Statistics in Saudi Arabia. This shows that people who know about cryptocurrency are well educated compared to the Saudi population. The majority of people who were involved in the study are highly educated, and their behavior may differ from the general population because it was shown that educated people are more prone to adopting new technologies easier (Welch, 1970; Lleras-Muney and Lichtenberg, 2002; Riddell and Song, 2017). Additionally, the study focused on people who already know about cryptocurrency so that the results can be applied only to a specific population segment. This may add biases to the results, as the opinions are not referring to the general population. Hence future studies will focus on other population segments.

This research has several implications. This study's results can be used by governments, corporations, and other decision-makers by incorporating the experimental factors into the development of cryptocurrency systems and strategies. Special attention should be paid to security risks by regulating the use of cryptocurrencies so that users have a clear understanding of the security risks they may face and how they can be protected from them. Also, users are more likely to embrace the new technology if they can see its benefits. It is, therefore, necessary to provide accurate information about the system. Since the model must offer the possibility of connecting the practical and theoretical aspects, the model's implication also includes the possibility of connecting the model with real situations. Since the presented model provides sufficient outcomes to be used and understood for various technology-related studies, new research in cryptocurrency adoption should be able to use this model as a theoretical basis. Finally, developers and decision-makers must consider the usefulness of cryptocurrency in developing such systems.

\section{References}

- Abramova, S., \&Böhme, R. (2016) Perceived benefit and risk as multidimensional determinants of bitcoin use: a quantitative exploratory study.

- $\quad$ Agarwal, R., \& Prasad, J. (1998) A conceptual and operational definition of personal innovativeness in the domain of information

technology. Information systems research, 9(2), pp. 204-215.

- Agustina, D. (2019) Extension of Technology Acceptance Model (Etam): Adoption of Cryptocurrency Online Trading Technology. JurnalEkonomi, 24(2), pp. 272-287.

- $\quad$ Al Shehhi, A., Oudah, M., \& Aung, Z. (2014) Investigating factors behind choosing a cryptocurrency. In 2014 IEEE international conference on industrial engineering and engineering management (pp. 1443-1447). IEEE.

- $\quad$ Alaeddin, O., \&Altounjy, R. (2018) Trust, technology awareness and satisfaction effect into the intention to use cryptocurrency among generation $\mathrm{Z}$ in Malaysia. International Journal of Engineering \& Technology, 7(4.27), pp. 8-10.

- Albayati, H., Kim, S. K., \& Rho, J. J. (2020) Accepting financial transactions using blockchain technology and cryptocurrency: A customer perspective approach. Technology in Society, 62, 101320.

- Alharbi, A., Kang, K., \&Hawryszkiewycz, I. (2016) The Influence of Trust and subjective Norms on Citizens Intentions to Engage in E-participation on Egovernment Websites. arXiv preprint arXiv:1606.00746.

- Alshamsi, A., \& Andras, P. (2019) User perception of Bitcoin 
usability and security across novice users. International Journal of Human-Computer Studies, 126, pp. 94-110.

- Al-Zoubi, S. I., \& Ali, M. (2019) Emobile Acceptance Using Unified Theory of Acceptance and Use of Technology (UTAUT): Research on Universities in Jordan. Annals of Emerging Technologies in Computing (AETiC), Print ISSN, pp. 2516-0281.

- $\quad$ Ayedh, A., Echchabi, A., Battour, M., \& Omar, M. (2020) Malaysian Muslim investors' behaviour towards the blockchain-based Bitcoin cryptocurrency market.Journal of Islamic Marketing.

- $\quad$ Belkhamza, Z., \&Wafa, S. A. (1970) The effect of perceived risk on the intention to use e-commerce: The case of Algeria. The Journal of Internet Banking and Commerce, 14(1), pp. 1-10.

- Davis, F. D. (1989) Perceived usefulness, perceived ease of use, and user acceptance of information technology. MIS quarterly, pp. 319340.

- Doblas, M. P. (2019) Awareness and attitude towards cryptocurrencies in relation to adoption among college students in a private tertiary institution in Cagayan De Oro City, Philippines. International Journal of Advanced Research and Publications, 3(4), pp. 15-19.

- Faqih, K. M. (2016) An empirical analysis of factors predicting the behavioral intention to adopt Internet shopping technology among non-shoppers in a developing country context: Does gender matter?.Journal of Retailing and Consumer Services, 30, pp. 140-164.

- Fishbein, M. (1976) A behavior theory approach to the relations between beliefs about an object and the attitude toward the object. In Mathematical Models in Marketing (pp. 87-88). Springer, Berlin, Heidelberg.
- Fishbein, M., \&Ajzen, I. (1975) Belief, attitude, intention, and behavior Reading. MA: AddisonWesley, pp. 913-927.

- Fishbein, M., Ajzen, I., Albarracin, D., \&Hornik, R. (2007) A reasoned action approach: Some issues, questions, and clarifications. Prediction and change of health behavior: Applying the reasoned action approach, pp. 281-295.

- Gibbs, T., \&Yordchim, S. (2014) Thai perception on Litecoin value. International Journal of Social, Behavioral, Educational, Economic, Business and Industrial Engineering, 8(8), pp. 2613-5.

- Global Data Lab, Subnational Human Development Index, 2019. https://globaldatalab.org/shdi/sh di/SAU/?levels=1\%2B4\&interpola tion $=0$ \&extrapolation $=0$ \&nearest $\underline{\text { real }=0}$

- GlobalMediaInsight. (2019) Dubai Web Design \& Development Agency, Social Media, SEO, Mobile Websites - GMI, UAE. [online] Available at: https://www.globalmediainsight.c om.

- Hale, J. L., Householder, B. J., \& Greene, K. L. (2002) The theory of reasoned action. The persuasion handbook: Developments in theory and practice, 14, pp. 259-286.

- Huang, J. H., Lin, Y. R., \& Chuang, S. T. (2007) Elucidating user behavior of mobile learning. The electronic library.

- Kannungo, S., \& Jain, V. (2004) Relationship between risk and intention to purchase in an online context: Role of gender and product category.

- Kaspersky.com. (2019) Uncharted territory: why consumers are still wary about adopting cryptocurrency. [online] Available at:

https://www.kaspersky.com/blog /cryptocurrency-report-2019/.

- Kishore, S. K., \&Sequeira, A. H. (2016) An empirical investigation on mobile banking service

Saad ALAKLABI and Kyeong KANG, Journal of Electronic Banking Systems, 
adoption in rural Karnataka. Sage Open, 6(1), pp.1-21.

- Ku-Mahamud, K. R., Omar, M., Bakar, N. A. A., \&Muraina, I. D. Awareness, Trust, and Adoption of Blockchain Technology and Cryptocurrency among Blockchain Communities in Malaysia.

- Lai, C. H., \& Tang, T. (2018) From information behaviors to disaster preparedness: Navigating individuals' general and disaster curation in US, China, and Australia. Computers in Human Behavior, 88, pp. 37-46.

- Lleras-Muney, A., \& Lichtenberg, F. R. (2002) The effect of education on medical technology adoption: are the more educated more likely to use new drugs(No. w9185). National Bureau of Economic Research.

- Martins, C., Oliveira, T., \&Popovič, A. (2014) Understanding the Internet banking adoption: A unified theory of acceptance and use of technology and perceived risk application. International Journal of Information Management, 34(1), pp. 1-13.

- Mendoza-Tello, J. C., Mora, H., Pujol-López, F. A., \&Lytras, M. D. (2018) Social commerce as a driver to enhance trust and intention to use cryptocurrencies for electronic payments. IEEE Access, 6, pp. 50737-50751.

- Mutambara, E. (2019) Predicting FinTech innovation adoption in South Africa: the case of cryptocurrency. African Journal of Economic and Management Studies, 1, pp. 30-50.

- $\quad$ Nadeem, M. A., Liu, Z., Pitafi, A. H., Younis, A., \& Xu, Y. (2020) Investigating the repurchase intention of Bitcoin: empirical evidence from China. Data Technologies and Applications.

- Nunnally, J. C. (1994) Psychometric theory 3E. Tata McGraw-hill education.

- Nuryyev, G., Wang, Y. P., Achyldurdyyeva, J., Jaw, B. S., Yeh,
Y. S., Lin, H. T., \& Wu, L. F. (2020) Blockchain Technology Adoption Behavior and Sustainability of the Business in Tourism and Hospitality SMEs: An Empirical Study. Sustainability, 12(3), pp. 1256.

- $\quad$ Riddell, W. C., \& Song, X. (2017) The role of education in technology use and adoption: Evidence from the Canadian workplace and employee survey. ILR Review,70(5), pp. 1219-1253.

- Schaupp, L. C., \&Festa, M. (2018)Cryptocurrency adoption and the road to regulation. In Proceedings of the 19th Annual International Conference on Digital Government Research: Governance in the Data Age, pp. 1-9.

- Shrestha, A. K., \&Vassileva, J. (2019) User Acceptance of Usable Blockchain-Based Research Data Sharing System: An Extended TAM-Based Study. In 2019 First IEEE International Conference on Trust, Privacy and Security in Intelligent Systems and Applications (TPS-ISA) pp. 203208.

- Sohaib, O., Hussain, W., Asif, M., Ahmad, M., \&Mazzara, M. (2019) A PLS-SEM neural network approach for understanding cryptocurrency adoption. IEEE Access, 8, pp. 13138-13150.ž

- $\quad$ Thakur, R., \& Srivastava, M. (2014) Adoption readiness, personal innovativeness, perceived risk and usage intention across customer groups for mobile payment services in India. Internet Research.

- Walton, A., \& Johnston, K. (2018) Exploring perceptions of bitcoin adoption: the South African virtual community perspective. Interdisciplinary Journal of Information, Knowledge \& Management, 13.

- Wang, G., Dou, W., \& Zhou, N. (2008) Consumption attitudes and adoption of new consumer products: a contingency 
approach. European Journal of Marketing,1/2 ,pp. 238-254.

- Welch, F. (1970) Education in production.Journal of political economy, 78(1), pp. 35-59.

- Won-jun, L. (2018).UnderstandingCounsumer Acceptance of Fintech Service: An Extension of the TAM Model to Understand Bitcoin. IOSR Journal of Business and Management, 20(7), pp. 34-37.

- Wood, J., Jang, H., Lenskiy, A., \& Khan, G. F. (2017) The diffusion and adoption of bitcoin: a practical survey for business. International Business Management, 11, pp. 1278-1288.

- Zarifis, A., Efthymiou, L., Cheng, X., \& Demetriou, S. (2014) Consumer trust in digital currency enabled transactions. In International Conference on Business Information Systems, pp. 241-254.

- $\quad$ Zong, W., Yang, J., \& Bao, Z. (2019) Social network fatigue affecting continuance intention of social networking services. Data Technologies and Applications. 53, pp. 123-139. 